\title{
'Complete 5p' trisomy: 1 case and 19 translocation carriers in 6 generations
}

\author{
F. S. W. BRIMBLECOMBE, F. J. LEWIS, AND M. VOWLES \\ From the Department of Paediatrics, Exeter, and the Cytogenetics Unit, Southmead, Bristol
}

SUMMARY A description is given of a female infant with multiple malformations and mental retardation who died at 31 months. Cytogenetic studies indicate trisomy of the complete short arm of chromosome 5, resulting from the unbalanced segregation of a balanced translocation in the mother whose karyotype was interpreted as $46, \mathrm{XX}, \mathrm{t}(5 ; 15)(\mathrm{p} 11 ; \mathrm{p} 12)$. The karyotype of the proband was designated $46, X X, \operatorname{der}(5) t(5 ; 15)(\mathrm{p} 11 ; \mathrm{pl} 2)$ mat. Family studies indicate that the translocation had been present in the family for at least 6 generations.

Six cases of partial trisomy of presumptive $5 p$ have been reported by Lejeune et al. (1964 and personal communication), Laurent and Robert (1966), de Capoa et al. (1967), and Noel et al. (1968).

We present a case which we believe to be the only recorded example of trisomy for the complete short arm of chromosome 5 (Brimblecombe and Lewis, 1966). The trisomic condition is the consequence of unbalanced segregation of a balanced translocation found in the mother and interpreted as $46, \mathrm{XX}, \mathrm{t}(5 ; 15)$ (p11; p 12).

\section{Case history}

The proband, Jennifer $\mathrm{K}$, was born normally at term after an uneventful pregnancy, and weighed $2410 \mathrm{~g}$. There was asymmetry of the face, with coloboma of the iris and microphthalmia affecting the left eye. The left ear was downwardly displaced and malformed, with a flattened helix (Fig. 1). Bilateral talipes equinovarus was present. At the age of 5 weeks a successful operation for pyloric stenosis was undertaken.

Her developmental progress was retarded so that by the age of 7 months her performance was that normally achieved by an infant of 2 months, and by the age of 30 months she had attained a developmental age of only 12 months. Her weight gain throughout was poor. She died suddenly at the age of 31 months, the cause of death being bronchopneumonia, which was confirmed at necropsy. The only additional abnormality found at this time was a small corpus callosum.

Received for publication 5 January 1977

\section{Cytogenetics}

Karyotypes from the proband were prepared from both peripheral blood and fibroblasts; karyotypes from the other members of the family were prepared from peripheral blood cultures only. In the proband each cell showed an unbalanced karyotype in which one D group chromosome was replaced by a submetacentric chromosome which was characterised by a conspicuous unstained segment in the short arm, proximal to the centromere. The abnormal chromosome was identified subsequently as one component of a balanced translocation carried not only by the

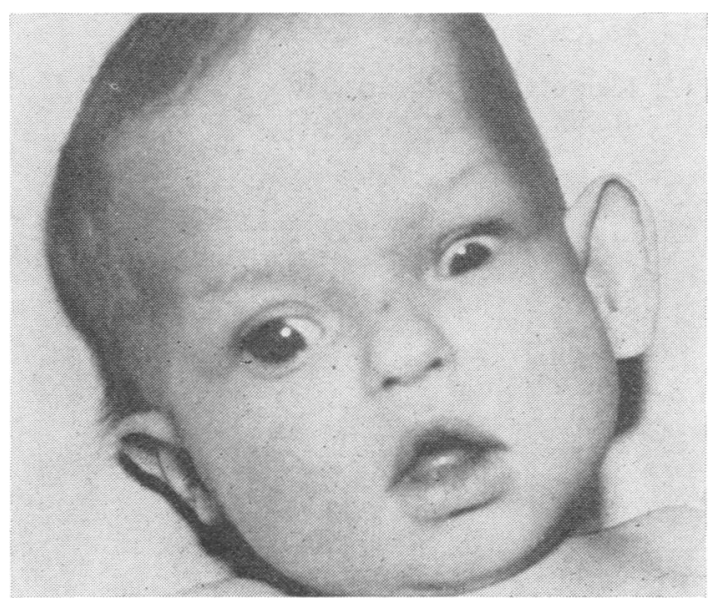

Fig. 1 Facies of proband, showing asymmetry, microphthalmia of left eye, and displaced and malformed left ear. 


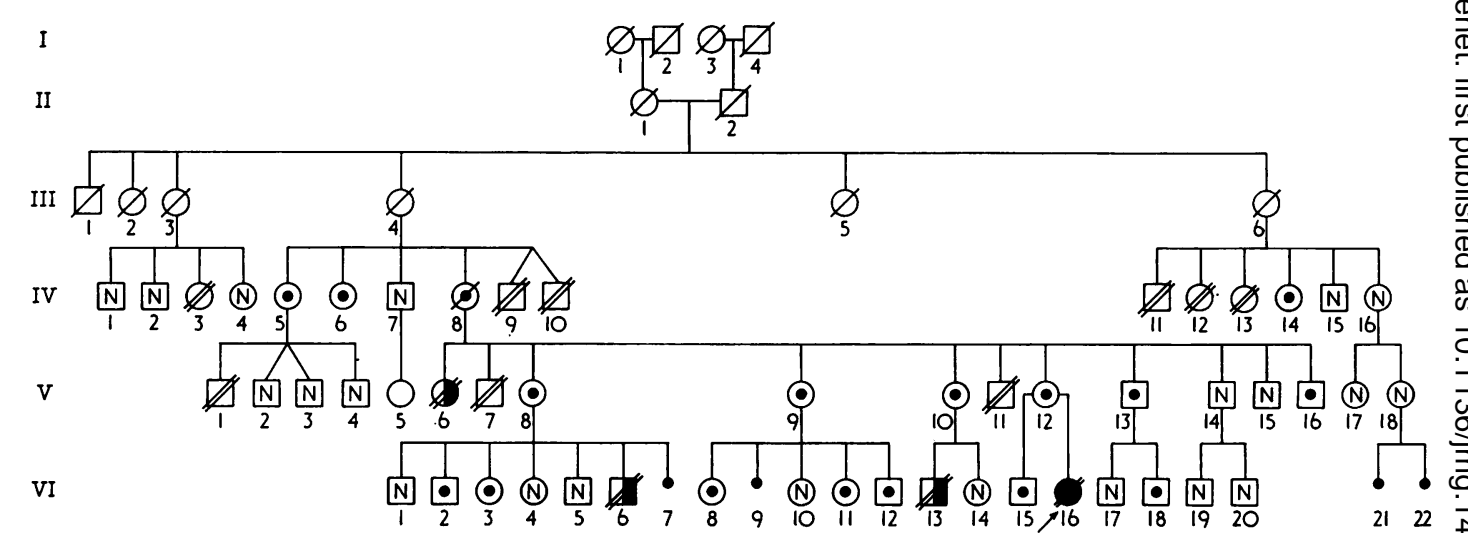

YProband $\odot$ 5-15 translocation corrier

(N) Normal karyotype

Not cytologically examined $\varnothing$ Dead

\&"Stillbirthor early death with abnormalities - Miscarriage

$\varnothing$ Stillbirth or eorly deothit

Fig. 2 Pedigree of family.

mother of the proband, but also by 16 other members of the family; furthermore, it can be inferred from the pedigree that another 2 members carried the same balanced translocation abnormality (see pedigree, Fig. 2). Autoradiographic studies indicated that the translocation involved the short arms of chromosome 5 and 15 (Fig. 3); more recent investigation using fluorescence and Giemsa banding techniques have identified the breakpoints more precisely as 5p11 and 15p12 (Fig. 4).

From these studies we conclude that the following two karyotypes apply:

(1) Karyotype of the proband: $46, X X, \operatorname{der}(5), t(5 ; 15)(\mathrm{p} 11 ; \mathrm{p} 12)$ mat

(2) Karyotype of the carriers: $46, X X$ or $X Y, t(5 ; 15)(p 11 ; p 12)$
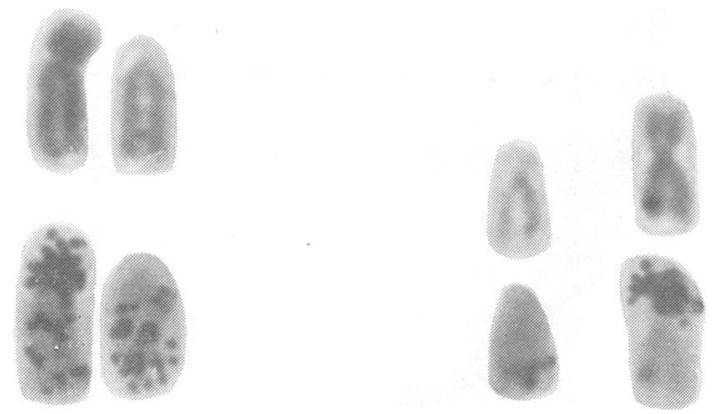

Fig. 3 Chromosomes 5 and 15, with autoradiographs below, showing balanced translocation in the mother of the proband.
Investigation of blood groups and red cell enzymes in the proband and 16 members of the family were undertaken by Dr E. Robson. No correlation of anye significance was found.

A study of the dermatoglyphs of the proband wasmade by the late Professor Penrose who reported 'On the finger-tips the pattern size was small, as is commonly found in trisomies, but no other abnormalities were demonstrated.'

\section{Family studies (Fig. 2)}

If we consider in Fig. 2, the relevant members of generations IV to VI known to have normal pheno= types (IV.1, 2, 4, 5, 6, 7, 8, 14, 15, 16; V.2, 3, 4, 8, 9.0 $10,12,13,14,15,16$; VI. $1,2,3,4,5,8,10,11,12,14$, $15,17,18)$ are 34 and of these 34 individuals there are 5 females with a normal karyotype and 11 femaleso with the balanced translocation; of the male popu lation in this group, 12 have normal karyotypes and 6 have balanced translocations. In the same 3 genera-D tions 13 individuals were stillborn or died in infancy를 (IV.3, 9, 10, 11, 12, 13; V.1, 6, 7, 11; VI.6, 13, 16); of these, 8 were male and 5 were female. We have been unable to ascertain whether malformations weres present in 9 of these 13 individuals; of the remaining $4, N$ V.1 was stated by her mother to have been born witho abnormalities the details of which were neither knowne to her nor recorded; VI.6 was a stillborn anence- $\frac{-}{\Phi}$ phalic; VI.13 had multiple skeletal abnormalities,? namely scaphocephaly, bilateral talipes equinovarus, 0 and spina bifida occulta; and the fourth was the proband whose malformations have already been described. 


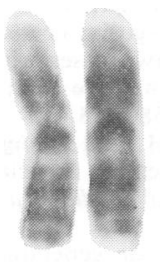

I

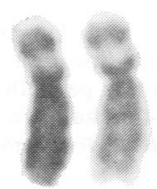

6

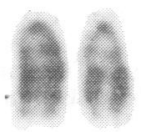

13

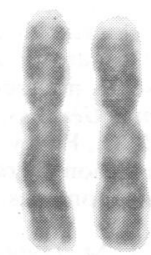

2

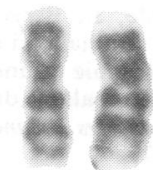

7

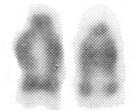

14

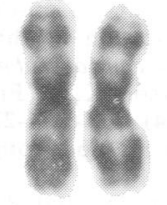

3

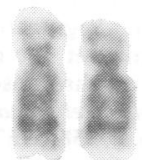

8

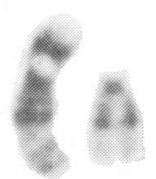

15

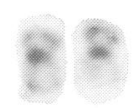

20

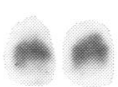

21

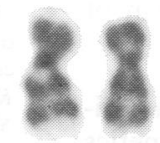

9

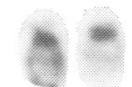

22

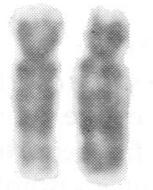

4

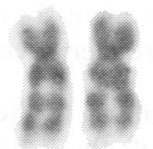

10

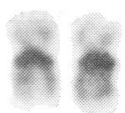

16

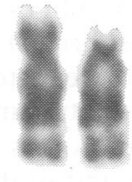

5

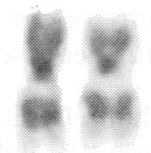

II

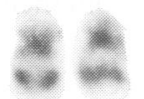

17

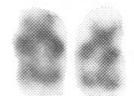

18

Fig. 4 Trypsin-Giemsa banded karyotype of a balanced carrier.

In all, 8 out of 10 female carriers (III.4, 6; IV.5, $8 ; \mathrm{V} .8,9,10,12)$ of the balanced translocation in generations III to V have had a total of 43 offspring; of these 13 are cytogenetically normal ( 9 male); 16 are translocation carriers ( 5 male); 12 were stillborn or died in infancy ( 8 male), and there were 2 miscarriages at approximately 20 weeks (sex unknown). There is only one male carrier of the balanced translocation who has had offspring; he has had 2 sons, 1 of whom is normal and 1 of whom is a carrier of the balanced translocation.

\section{Discussion}

Partial trisomy of presumptive $5 p$ was first described in 2 sibs by Lejeune et al. (1964 and personal communication), 1 being a baby who died in infancy, and the other a girl who is still living but severely mentally retarded. Both these patients showed asymmetry of the jaw similar to that found in our proband. Laurent and Robert (1966 and personal communication) illustrated a third case with a similar asymmetry of the jaw. De Capoa et al. (1967) described a further 2 cases with minor clinical defects, and in their review underlined the non-specificity, wide range, and relative mildness (apart from mental retardation) of their abnormalities. Finally a sixth case has been described by Noel et al. (1968), with minor physical abnormalities but severe mental retardation.

These are all partial trisomies of presumptive $5 p$. Complete trisomy of the short arm of an unidentified B group chromosome has been described by Gustavson et al. (1954), the patient having severe multiple abnormalities and dying at the age of 3 months. Some of the patient's abnormalities were similar to those found in our proband, namely scaphocephaly, scoliosis, macroglossia, and malformations of ear and long fingers and toes. It is of interest that asymmetry of the jaw was not present in Gustavson's case.

On the other hand, some of these malformations, namely scaphocephaly, macroglossia, malformations 
of the ears, and narrow palpebral fissures were also found in 1 or more of 4 cases of $4 p$ trisomy described by Schinzel and Schmid (1972), Owen et al. (1974), and Darmady and Seabright (1975).

Therefore, there, appears to be some overlap of the clinical findings in the trisomies of the short arm of the B group chromosomes so far reported, comparable with that found in the chromosomal abnormalities of other groups. It is probable that a distinct phenotype associated with trisomy of the complete short arm of chromosome 5 will only be distinguished from that of trisomy of the complete short arm of chromosome 4 as further cases are identified.

We would like to thank Dr E. Robson for her investigations; the laboratory staff of the Cytogenetics Unit, Southmead Hospital, Bristol, for their technical assistance; Dr A. McDermott for his helpful advice in reviewing this report, and finally all the doctors who assisted us in tracing members of the family and obtaining samples from them for cytogenetic studies.

\section{References}

Brimblecombe, F. S. W., and Lewis, F. J. W. (1966). Presumptive trisomy of the short arm of B5 chromosome. Human Chromosome Newsletter, Vol. 18, p. 6.

Darmady, J. H., and Seabright, M. A. (1975). A family with an inherited translocation involving the No. 4/No. 21 chromosomes. Journal of Medical Genetics, 12, 408-411. de Capao, A. Warburton, D., Breg, W. R., Miller, D. A., and Miller, O. J. (1967). Translocation heterozygosis: a cause of five cases of cri-du-chat syndrome and two cases with duplication of chromosome number 5 in three familieso American Journal of Human Genetics, 19, 586-603.

Gustavson, K. H., Finley, S. C., Finley, W. H., and Jalling, $\mathrm{R}^{\circ}$ (1964). A 4-5/21-22 chromosomal translocation associate 9 with multiple congenital anomalies. Acta Paediatrica 5is 172-181.

Laurent, D., and Robert J. M. (1966). Etude genetique ef clinique d'une famille de sept enfants dans laquelle trof sujets son atteints de la 'maladie due cri-du-chat'. Annals de Génétique, 9, 113-122.

Lejeune, J., La Fourcade, J., Berger, R., and Turpin, R. (1964). Segregation familiale d'un translocation 5-19ু determinant une monosomie et une trisomie partielle bras. court du chromosome 5: maladie du 'cri-du-chat'. Comptes Rendus Hebdomadaires des Séances de l'Académie dês Sciences, 258, 5767-5770.

Noel, B., Quack, B., and Thinet, M. (1968). Segregation d'uni translocation balances t/5p-; 9p+) Annales de Génétiquñ

11, 247-252.
Owen L., Martin B., Blank, C. E., and Harris, F. (1974) Multiple congenital defects associated with trisomy for tho short arm of chromosome 4. Journal of Medical Genetics, 11, 291-295.

Schinzel, A., and Schmid, W. (1972), Partiel Trisomie d\&્ฮ kurgen Armes von Chromosome 4 mit Tranlokation 4p$18 \mathrm{q}+$ beim Vater. Humangenetik, 15, 163-171.

Requests for reprints to Dr F. S. W. Brimblecombe, Royal Devon and Exeter Hospital (Heavitree? Gladstone Road, Exeter EX1 2ED. 